\section{Ocular blood flow changes after dynamic exercise in humans}

T Okuno, T Sugiyama, M Kohyama, S Kojima, H Oku and T Ikeda
Department of

Ophthalmology, Osaka Medical College,

Takatsuki, Osaka, Japan

Correspondence:

T Sugiyama, Department of Ophthalmology, Osaka Medical College, 2-7

Daigaku-cho, Takatsuki, Osaka, 569-8686 Japan Tel: +81726831221 ;

Fax: +81726818195 .

E-mail: opt017@

poh.osaka-med.ac.jp

Received: 12 December 2004

Accepted in revised form:

1 June 2005;

Published online:

8 July 2005

\begin{abstract}
Purpose To investigate control mechanisms for ocular blood flow changes after dynamic exercise using two different methods. Methods Changes over time in the tissue blood flow in the retina and choroid-retina of healthy volunteers were determined after dynamic exercise (Master's double two-step test), using scanning laser Doppler flowmetry (SLDF) and laser speckle flowgraphy (LSFG). Changes in intraocular pressure (IOP), blood pressure, plasma $\mathrm{CO}_{2}$ gas concentration $\left(\mathrm{pCO}_{2}\right)$, and levels of nitric oxide (NO) metabolites were examined.

Results Retinal blood flow measured by SLDF increased significantly only at $15 \mathrm{~min}$ after exercise. In contrast, normalized blur (NB) values in the choroid-retina, obtained by LSFG, increased significantly up to $60 \mathrm{~min}$ after exercise. Ocular perfusion pressure (OPP), calculated from IOP and blood pressure, increased significantly immediately and $15 \mathrm{~min}$ after exercise. The plasma NO metabolite levels increased significantly, although $\mathrm{pCO}_{2}$ levels were unchanged.

Conclusions Dynamic exercise changes OPP and produces increased tissue blood flow in the retina in the immediate postexercise period, while blood flow increases more persistently in the choroid-retina. Difference in control of blood flow in these two regions may be related to stronger autoregulatory mechanism of blood flow in the retina. Nitric oxide may play a role in the regulation of blood flow.

Eye (2006) 20, 796-800. doi:10.1038/sj.eye.6702004; published online 8 July 2005
\end{abstract}

Keywords: dynamic exercise; blood flow; retina; choroids; nitric oxide
Introduction

Studies of exercise effects on blood flow in ocular structures typically involve either isometric exercise $\mathrm{e}^{1-4}$ or, in a few cases, dynamic exercise. ${ }^{5,6}$ Previous reports employed a blue field stimulator and video fluorescein angiography to estimate retinal blood flow. In this study, we investigate changes in ocular blood flow after dynamic exercise in healthy volunteers, using two methods: scanning laser Doppler flowmetry (SLDF) and laser speckle flowgraphy (LSFG) ${ }^{7,8}$ that has been developed recently in Japan. To investigate mechanisms regulating blood flow, we also examined changes in blood gases, including $\mathrm{CO}_{2}$ and nitric oxide $(\mathrm{NO})$ metabolites.

\section{Methods}

\section{Subjects}

The subjects were 10 healthy volunteers without any ophthalmologic disorders (other than simple myopia): six male and four female volunteers ranging in age from 23 to 53 (mean 30.2 ) years old. One eye was measured in each volunteer, randomized for left or right. The institutional review board of Osaka Medical College approved consent forms for this study. The aim and procedure of the study were explained to each subject, and consent forms were taken prior to participation. The study was carried out in conformity with the tenets of the Declaration of Helsinki.

\section{Study design}

The subjects were asked to abstain from caffeine, ${ }^{9}$ alcohol, ${ }^{10}$ and smoking ${ }^{11}$ for $6 \mathrm{~h}$ preceding the study. Exercise was also prohibited for $1 \mathrm{~h}$ before the study. Subjects were seated on chairs in a quiet room maintained at $20-25^{\circ} \mathrm{C}$ prior to the exercise 
period. Subjects were instructed to perform $6 \mathrm{~min}$ of exercise with an equalized load-degree, that is Master's double two-step test consisting of stepping onto and off two $23 \mathrm{~cm}$ steps at a predefined rate. ${ }^{12}$ Blood pressure and intraocular pressure (IOP) as well as ocular blood flow were measured in one eye before and after the exercise at $15 \mathrm{~min}$ intervals for $1 \mathrm{~h}$. Venous blood was sampled before and $15 \mathrm{~min}$ after the exercise for determination of blood gases.

\section{Ocular blood flow measurement by SLDF}

The principle of SLDF for measurement of ocular blood flow has been described elsewhere. ${ }^{13-15}$ Briefly, this noninvasive technique combines laser Doppler flowmetry and the principle of confocal laser scanning. Laser Doppler flowmetry uses the optical Doppler effect to measure the volume and velocity of moving red blood cells. The confocal scanning laser technique enables twodimensional mapping of ocular perfusion. SLDF images $10 \times 2.5$ degrees of the retina with a scanning $780 \mathrm{~nm}$ infrared laser. The process scans 64 horizontal lines 128 times within $2.048 \mathrm{~s}$ with a line repetition rate of $4000 \mathrm{~Hz}$. By performing a discrete, fast Fourier transformation over 128 scans of each retinal point, a power spectrum is obtained and the independent variables of volume and flow are calculated.

Ocular blood flow measurements were obtained using a Heidelberg Retina Flowmeter (Heidelberg Engineering, Dossenheim, Germany). The measurement field was $100 \times 100 \mu \mathrm{m}$. Subjects were asked to fixate a distant static target during the measurements. The measurement field was an area between the macula and the optic nerve head $(\mathrm{ONH})$ free of surface vessels. For each subject, images of poor quality, mainly due to gross eye movements and poor fixation were excluded from the analysis. Values from five images of good quality were chosen and three values (excluding the maximum and minimum) were averaged to obtain the data.

\section{Ocular blood flow measurement by LSFG}

The mechanism of LSFG has been described in previous publications. ${ }^{7,8}$ The system consists of a fundus camera (TRC-WT3, Topcon, Tokyo, Japan) equipped with a diode laser (wavelength $808 \mathrm{~nm}$ ). The scattered laser light is imaged on a sensor $(100 \times 100$ pixels, BASIS type, Canon, Tokyo, Japan) and corresponds to the $0.72 \times 0.72 \mathrm{~mm}$ field ( $30^{\circ}$ visual angle) in the human ocular fundus, where the speckle pattern appears. The normalized blur (NB) value is an approximate reciprocal of speckle contrast related to the interference pattern produced when laser light is scattered by the retina and choroid.
This value serves as an indicator of blood flow as well as blood velocity.7,8

Before the recording, one drop of $0.4 \%$ tropicamide (Mydrin $\mathrm{M}^{\circledR}$, Santen, Osaka, Japan) was instilled into the randomly chosen eye to induce mydriasis. The image speckles were recorded every $0.125 \mathrm{~s}$ for $7 \mathrm{~s}$ for measurement of NB values in the choroid-retina, with NB values averaged for 4-6 cardiac cycles for each data point.

\section{Measurements of blood pressure and IOP}

Brachial arterial blood pressure and pulse rate were measured using an automated sphygmomanometer (JENTOW-7700 (CS), Nippon Colin, Komaki, Japan). Mean blood pressure (BPm) was calculated from systolic blood pressure (BPs) and diastolic blood pressure (BPd), according to the following equation:

$$
\mathrm{BPm}=\mathrm{BPd}+1 / 3(\mathrm{BPs}-\mathrm{BPd})
$$

IOP was measured with a Goldmann applanation tonometer after determination of the NB value. Using the $\mathrm{IOP}$ and $\mathrm{BPm}$, ocular perfusion pressure (OPP) was calculated using the following equation:

$$
\mathrm{OPP}=2 / 3 \mathrm{BPm}-\mathrm{IOP}
$$

\section{Blood gas analysis}

Venous blood was collected from the median cubital vein. The plasma $\mathrm{CO}_{2}$ gas concentration $\left(\mathrm{pCO}_{2}\right)$ was determined by an automatic blood gas analysis system (Stat Profile V, NOVA Biomedical, Waltham, MA). The plasma nitric oxide (NO) metabolite level was measured by an automated NO detector-highperformance liquid chromatography (HPLC) system (EN0-20; Eicom, Kyoto, Japan). This method has been used to detect NO levels in the eye, ${ }^{16,17}$ and the procedures are described in detail elsewhere. ${ }^{18}$ Nitrite and nitrate in the dialysate were separated by a reversedphase separation column packed with polystyrene polymer (NO-PAK, $4.6 \times 50 \mathrm{~mm}$, Eicom). The nitrate in the sample was reduced in a cadmium column (NORED, Eicom) to nitrite, which reacts with the Griess reagent naphthylethylenediamine to form a purple azo dye, while the nitrite in the sample bypasses the cadmium column for measurements. The levels of nitrite and nitrate in the $10 \mathrm{~min}$ dialysate sample were determined by measuring the absorbance of the colour product at $540 \mathrm{~nm}$ by a flow-through spectrophotometer (NOD-10, Eicom). 


\section{Statistics}

Since the retinal blood flow obtained by SLDF and the NB values are not absolute values, they were analysed by nonparametric test, for example, Friedman test and Wilcoxon signed rank test. The data for blood pressure, IOP, OPP, and blood gas exhibit approximately normal distributions and changes from baseline were analysed using analysis of variance (ANOVA) methods and paired $t$-tests. In all tests, $P<0.05$ was the criterion employed to declare statistically significant differences.

\section{Results}

\section{Ocular blood flow change measured by SLDF}

Retinal blood flow increased immediately after exercise then returned to baseline values by $45 \mathrm{~min}$ after cessation of exercise. Increases at $15 \mathrm{~min}$ were initially significant $(P<0.05$, Figure 1) but transient; at $30 \mathrm{~min}$, values were not significantly different from baseline values.

\section{Ocular blood flow change measured by LSFG}

NB values in the choroid-retina increased significantly after exercise $(P<0.01$, Figure 2$)$ increasing gradually during the 60-min observation period. The greatest increment from the previous value occurred at $30 \mathrm{~min}$ and the value at $60 \mathrm{~min}$ was still significantly higher than the previous level.

\section{Changes in blood pressure, IOP, and OPP}

Mean blood pressure increased immediately and $15 \mathrm{~min}$ after exercise (Figure 3); in contrast, IOP was reduced at

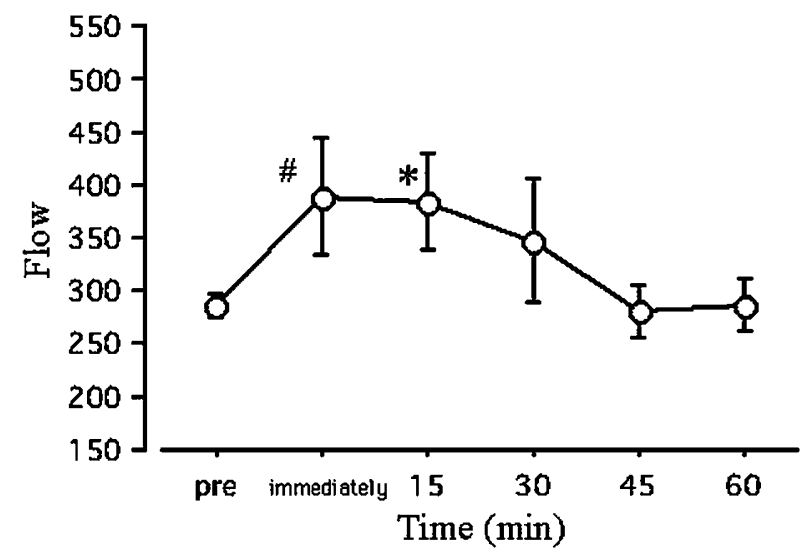

Figure 1 Changes in retinal blood flow after exercise, obtained by scanning laser Doppler flowmetry. Vertical bars represent the standard error of the mean (SEM). The blood flow increased significantly (Friedman test, $P<0.01, n=10$ ) only at $15 \mathrm{~min}$ compared with the previous value (Wilcoxon signed rank test, $\left.{ }^{*} P<0.05,{ }^{\#} P<0.1\right)$. least for an hour after exercise (Figure 4). The OPP calculated from the mean blood pressure and IOP increased immediately and $15 \mathrm{~min}$ after exercise (Figure 5).

\section{Blood gas changes}

Plasma concentrations of $\mathrm{NO}$ metabolites increased significantly after exercise $(P=0.047)$, although $\mathrm{pCO}_{2}$ levels were not changed significantly $(P=0.714$, Table 1$)$.

\section{Discussion}

In our current study, the ocular blood flow increased significantly after dynamic exercise. There have been a

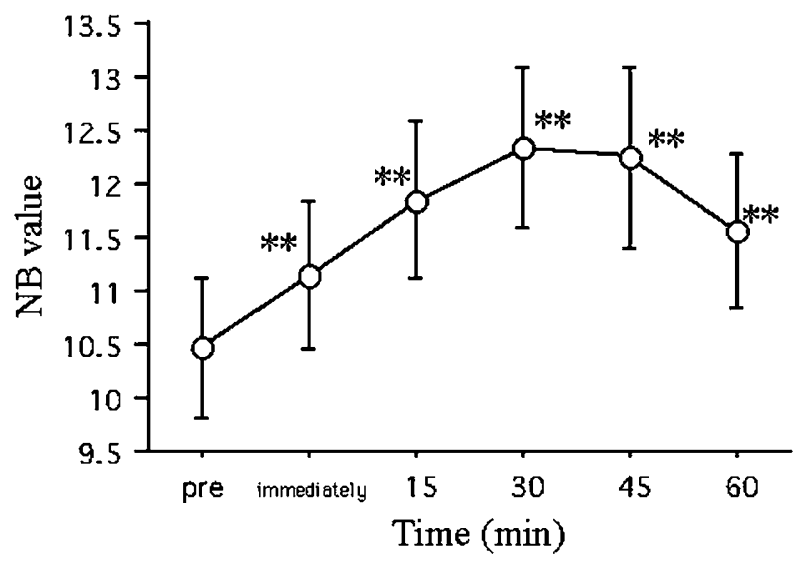

Figure 2 The changes in the NB values in the choroid-retina after exercise, measured by laser speckle flowgraphy. They increased significantly (Friedman test, $P<0.01, n=10$ ) from 15 to 60 min compared with the previous value (Wilcoxon signed rank test, $* P<0.05$ )

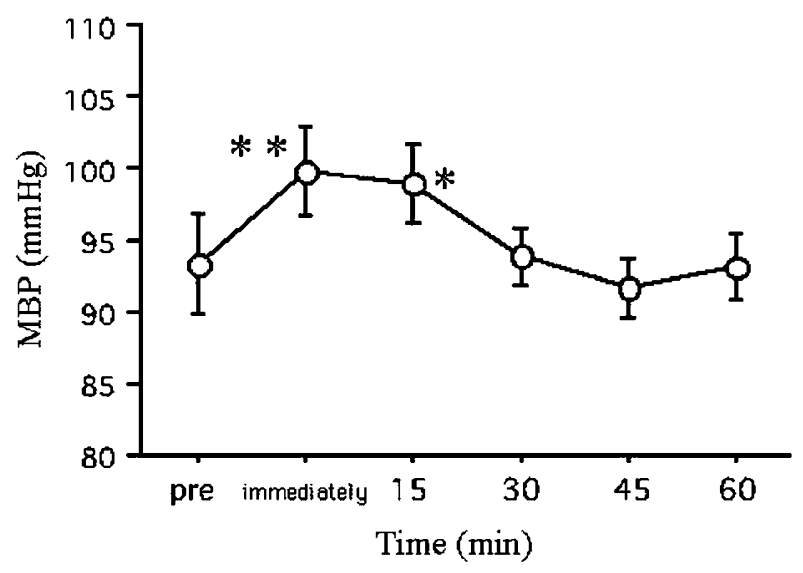

Figure 3 The changes in mean blood pressure (MBP) after exercise. The MBP showed a significant elevation (repeated measures ANOVA, $P<0.01, n=10)$ immediately and $15 \mathrm{~min}$ (paired $t$-test, ${ }^{* *} P<0.01$ and ${ }^{*} P<0.05$, respectively) after exercise. 


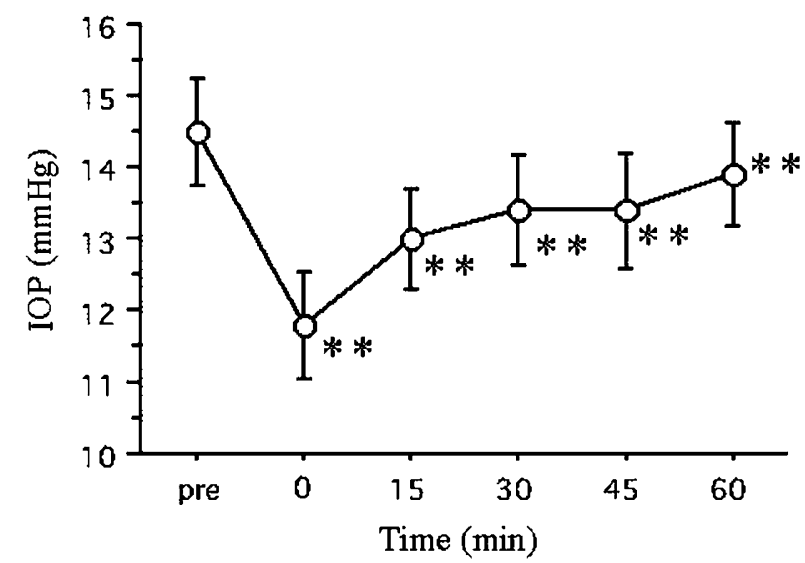

Figure 4 The changes in intraocular pressure (IOP) after exercise. The IOP decreased significantly (repeated measures ANOVA, $P<0.001, n=10$ ) at each time point (paired $t$-test, $\left.{ }^{* *} P<0.01\right)$ during the study.

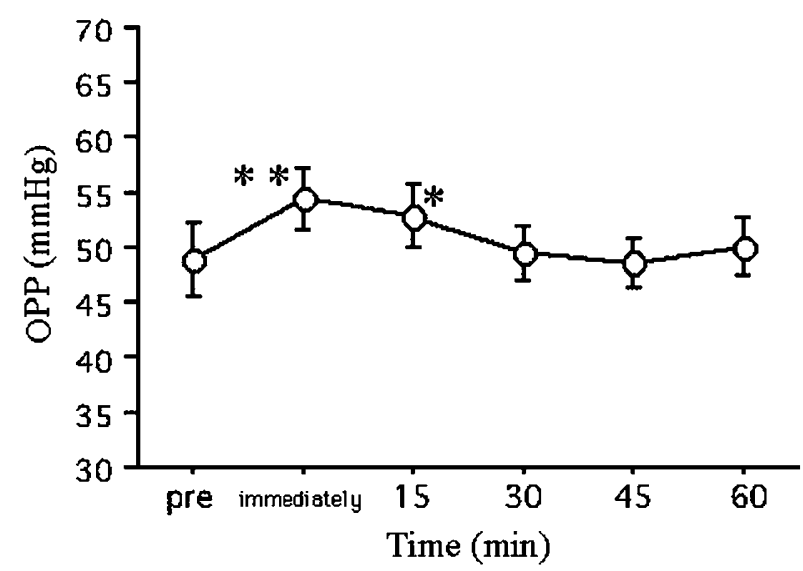

Figure 5 The changes in ocular perfusion pressure (OPP) after exercise. The OPP increased significantly (repeated measures ANOVA, $P<0.01, n=10$ ) immediately and $15 \mathrm{~min}$ (paired $t$-test, ${ }^{* *} P<0.01$ and ${ }^{*} P<0.05$, respectively) after exercise.

Table 1 The changes in concentration of nitric oxide metabolite and $\mathrm{pCO}_{2}$ after exercise

\begin{tabular}{lllr}
\hline & \multicolumn{1}{c}{ Before } & \multicolumn{1}{c}{ After } & P value \\
\hline No metabolites $(\mu \mathrm{M})$ & $26.48 \pm 10.38$ & $35.93 \pm 15.56$ & 0.047 \\
$\mathrm{CO}_{2}$ (Torr) & $43.60 \pm 6.60$ & $42.81 \pm 2.87$ & 0.714 \\
\hline
\end{tabular}

The plasma nitric oxide metabolite increased significantly (Wilcoxon signed rank test, $P<0.05, n=10$ ), although $\mathrm{pCO}_{2}$ levels were unchanged (Wilcoxon signed rank test, $P=0.93, n=10$ ).

small number of reports assessing ocular blood flow changes induced by dynamic exercise., ${ }^{5,6}$ One report suggested that large retinal arteries constricted to normalize the blood flow in spite of increased OPP after exercise. ${ }^{5}$ Our results suggest that autoregulatory mechanisms for ocular blood flow may increase retinal and choroidal tissue circulation when large ocular arteries constrict during exercise.

Blood gases showed differential responses to exercise, with $\mathrm{pCO}_{2}$ remaining unchanged but plasma $\mathrm{NO}$ metabolites increasing after dynamic exercise. Since the NO metabolites are relatively stable, serum NO levels can be estimated from the measured levels of NO metabolites in the blood sample. ${ }^{19}$ Several reports show that NO regulates blood flow in the eyes..$^{20-22}$ In addition, $\mathrm{NO}$ is involved in regulation of blood flow in organs after exercise and these actions may confound detection of $\mathrm{NO}$ effects in the eye during whole body exercise. ${ }^{23-27}$ Therefore, NO may play an important role in the mechanism of blood flow changes in ocular and other tissues after exercise. It might be concluded that plasma NO changes explain the changes in ocular blood flow after dynamic exercise from the present experiments. However, it may well be that a number of other substances affecting ocular blood flow are increased after exercise.

Several studies using laser Doppler velocimetry ${ }^{1-3}$ and a new laser interferometric technique ${ }^{4}$ report unchanged ocular blood flow during isometric exercise. Riva et $a l^{2}$ reported an increase in choroidal vascular resistance that limited increases in choroidal blood flow when OPP increased up to $67 \%$, but this regulatory process failed when OPP increased further. Movaffaghy $e t \mathrm{al}^{3}$ reported no significant variation in mean velocity, volume, and flow of red blood cells in the range of OPP from 56 to $80 \mathrm{mmHg}$, with increased vascular resistance. Kiss et al ${ }^{4}$ reported that isometric exercise caused significant increases in choroidal blood flow only when OPP also increased over $69 \%$, but this effect was associated with significant concurrent increases in mean arterial pressure and pulse rate. Based on these reports, the OPP change in our study seems to be in the range within which the autoregulatory mechanism is active. Thus, our results seem to be contradictory to those previous reports. The reason is uncertain and hard to explain completely; however, two explanations may be possible. For the first, different types of exercise (isometric $v s$ dynamic) may involve differential regulatory mechanisms. Dynamic exercise may stimulate many transmitters and induce more systemic metabolic changes than the more systemically limited isometric exercise. In the previous reports, ${ }^{1-4}$ isometric exercise was probably selected as the best method for increasing OPP without inducing much systemic metabolic change. Dynamic exercise, however, has more relevance to normal physiologic conditions and daily life. We hypothesize that the autoregulatory range of OPP may be different during dynamic exercise compared to isometric exercise. ${ }^{1-4}$

A second explanation of the divergence between previous reports and our findings may be due to the 
methods used to measure ocular blood flow. With the Heidelberg Retina Flowmeter, retinal blood flow can be measured down to only $300 \mu \mathrm{m}$ tissue depth. ${ }^{15}$ In contrast, LSFG can measure blood flow not only in the retina but also in the choroid, where the latter reflects $3 / 4$ of the total measured values. ${ }^{28}$ Different measurement fields (Heidelberg Retina Flowmeter: $0.1 \times 0.1 \mathrm{~mm}$; LSFG: $0.72 \times 0.72 \mathrm{~mm}$ ) could also produce some of the difference between the two measurement methods.

In conclusion, the present results indicate that retinal blood flow increases immediately after exercise, but choroidal blood flow increases slowly during the exercise period. NO may have an important role in the blood flow change.

\section{References}

1 Dumskyj MJ, Eriksen JE, Dore CJ, Kohner EM. Autoregulation in the human retinal circulation: assessment using isometric exercise, laser Doppler velocimetry, and computer-assisted image analysis. Microvasc Res 1996; 51: 378-392.

2 Riva CE, Titze P, Hero M, Movaffaghy A, Petrig BL. Choroidal blood flow during isometric exercises. Invest Ophthalmol Vis Sci 1997; 38: 2338-2343.

3 Movaffaghy A, Chamot SR, Petrig BL, Riva CE. Blood flow in the human optic nerve head during isometric exercise. Exp Eye Res 1998; 67: 561-568.

4 Kiss B, Dallinger S, Polak K, Findl O, Eichler HG, Schmetterer L. Ocular hemodynamics during isometric exercise. Microvasc Res 2001; 61: 1-13.

5 Harris A, Arend O, Bohnke K, Kroepfl E, Danis R, Martin B. Retinal blood flow during dynamic exercise. Graefes Arch Clin Exp Ophthalmol 1996; 234: 440-444.

6 Forcier P, Kergoat H, Lovasik JV. Macular hemodynamic responses to short-term acute exercise in young healthy adults. Vision Res 1998; 38: 181-186.

7 Tamaki Y, Araie M, Kawamoto E, Eguchi S, Fujii H. Noncontact, two-dimensional measurement of tissue circulation in choroid and optic nerve head using laser speckle phenomenon. Exp Eye Res 1995; 60: 373-384.

8 Sugiyama T, Utsumi T, Azuma I, Fujii H. Measurement of optic nerve head circulation: comparison of laser speckle and hydrogen clearance methods. Jpn J Ophthalmol 1996; 40: 339-343.

9 Okuno T, Sugiyama T, Tominaga M, Kojima S, Ikeda T. Effect of caffeine on microcirculation of human ocular fundus. Jpn J Ophthalmol 2002; 46: 170-176.

10 Kojima S, Sugiyama T, Kojima M, Azuma I, Ito S. Effect of the consumption of ethanol on the microcirculation of the human optic nerve head in the acute phase. Jpn J Ophthalmol 2000; 44: 318-319.

11 Tamaki Y, Araie M, Nagahara M, Tomita K. Acute effects of cigarette smoking on tissue circulation in human optic nerve head and choroid-retina. Ophthalmology 1999; 106: 564-569.
12 Master AM. Master's two-step test. Am Heart J 1968; 75: 809-821.

13 Michelson G, Schmauss B, Langhans MJ, Harazny J, Groh MJ. Principle, validity, and reliability of scanning laser Doppler flowmetry. J Glaucoma 1996; 5: 99-105.

14 Kagemann L, Harris A, Chung SC, Evans D, Buck S, Martin B. Heidelberg retinal flowmetry: factors affecting blood flow measurement. Br J Ophthalmol 1998; 82: 131-136.

15 Zinser G. Scanning laser Doppler flowmetry. Principle and technique. In: Pillunat LE, Harris A, Anderson DR, Greve EL (eds). Current Concepts on Ocular Blood Flow in Glaucoma. Kugler Publications: The Hague, 1999, pp 197-204.

16 Okuno T, Oku H, Sugiyama T, Yang Y, Ikeda T. Evidence that nitric oxide is involved in autoregulation in optic nerve head of rabbits. Invest Ophthalmol Vis Sci 2002; 43: 784-789.

17 Okuno T, Oku H, Sugiyama T, Goto W, Ikeda T. Evaluation of nitric oxide synthesis in the optic nerve head in vivo using microdialysis and high-performance liquid chromatography and its interaction with endothelin-1. Ophthalmic Res 2003; 35: 78-83.

18 Yao T, Suzuki S, Nishino H, Nakahara T. On-line amperometric assay of glucose, L-glutamate, and acetylcholine using microdialysis probes and immobilized enzyme reactors. Electroanalysis 1995; 7: 1114-1117.

19 Menyawi IE, Looareesuwan S, Knapp S, Thalhammer F, Stoiser B, Burgmann H. Measurement of serum nitrite/ nitrate concentrations using high-performance liquid chromatography. J Chromatogr B Biomed Sci Appl 1998; 706: 347-351.

20 Koss MC. Functional role of nitric oxide in regulation of ocular blood flow. Eur J Pharmacol 1999; 374: 161-174.

21 Sugiyama T, Oku H, Ikari S, Ikeda T. Effect of nitric oxide synthase inhibitor on optic nerve head circulation in conscious rabbits. Invest Ophthalmol Vis Sci 2000; 41: 1149-1152.

22 Schmetterer L, Polak K. Role of nitric oxide in the control of ocular blood flow. Prog Retin Eye Res 2001; 20: 823-847.

23 Wilson JR, Kapoor S. Contribution of endothelium-derived relaxing factor to exercise-induced vasodilation in humans. J Appl Physiol 1993; 75: 2740-2744.

24 Dyke CK, Proctor DN, Dietz NM, Joyner MJ. Role of nitric oxide in exercise hyperaemia during prolonged rhythmic handgripping in humans. J Physiol 1995; 488(Part 1): 259-265.

25 Green DJ, O'Driscoll G, Blanksby BA, Taylor RR. Control of skeletal muscle blood flow during dynamic exercise: contribution of endothelium-derived nitric oxide. Sports Med 1996; 21: 119-146.

26 Dietz NM, Engelke KA, Samuel TT, Fix RT, Joyner MJ. Evidence for nitric oxide-mediated sympathetic forearm vasodiolatation in humans. J Physiol 1997; 498(Part 2): 531-540.

27 Shen W, LundborgM, Wang J, Stewart JM, Xu X, Ochoa M et al. Role of EDRF in the regulation of regional blood flow and vascular resistence at rest and during exercise in conscious dogs. J Appl Physiol 1994; 77: 165-172.

28 Isono H, Kimura Y, Aoyagi K, Fujii H, Konishi N. Analysis of choroidal blood flow by laser speckle flowgraphy. J Jpn Ophthalmol Soc 1997; 101: 684-691. 